Aletria, Belo Horizonte, v. 31, n. 1, p. 79-100, 2021

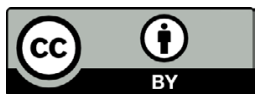

\title{
A recepção crítica do projeto editorial da Field Day Anthology of Irish Writing
}

\section{The Critical Reception of the Field Day Anthology of Irish Writing: Anathemata, Beatification or Canonization Lurking in a Biographical Note}

\author{
Maria Rita Drumond Viana \\ Universidade Federal de Santa Catarina (UFSC), Florianópolis, Santa Catarina / Brasil \\ m.rita.viana@ufsc.br \\ https://orcid.org/0000-0002-1985-3375 \\ Vinícius Garcia Valim \\ Universidade Federal de Santa Catarina (UFSC), Florianópolis, Santa Catarina / Brasil \\ vinicius.garcia.valim@gmail.com \\ http://orcid.org/0000-0001-7596-0856
}

Resumo: Verdadeiro evento editorial, a publicação de três volumes da Field Day Anthology of Irish Writing (1991) foi extensivamente resenhada em jornais de ampla circulação e periódicos da Irlanda, Reino Unido e EUA. Com objetivos indissociáveis das tensões políticas acerca do status político da Irlanda do Norte antes do Acordo de Paz de 1998, os volumes I a III foram alvo de amplo escrutínio por parte de jornalistas e críticos. Foram aqui selecionadas resenhas que abordam questões caras aos estudos editoriais e que raramente figuram na imprensa popular, como vieses de seleção, autoridade do aparato crítico, discurso editorial e materialidade dos livros. Concluímos que a reação à publicação original nos anos 1990 foi diretamente responsável pela edição de mais volumes publicados em 2002 e reflete mudanças da percepção do papel do projeto editorial em antologias nacionais.

Palavras-chave: Field Day Anthology of Irish Writing; antologias; projeto editorial; recepção crítica; estudos irlandeses. 


\begin{abstract}
A veritable editorial event, when the three-volume Field Day Anthology of Irish Writing was published in 1991 it extensively reviewed in wide-circulation periodicals and journals in Irelands, the UK, and the US. Its aims are inseparable from the political tensions over the political status of Northern Ireland before the Good Friday Agreement of 1998, and volumes I to III were subject to ample scrutiny by journalists and academics. The reviews deal with matters dear to textual and editorial studies but that rarely feature in the popular press, including selection bias, the authority of the critical apparatus, editorial discourse, and materiality. The reaction to the original 1990s publication was directly responsible for the commission of additional volumes that came out in 2002 and reflects changes in how the role of the editorial project is perceived.
\end{abstract}

Keywords: Field Day Anthology of Irish Writing; anthologies; editorial project; critical reception; Irish studies.

Fundada num primeiro momento como companhia de teatro, a Field Day tornou-se, ao longo dos anos 1980, uma produtora cultural de peso nas Irlandas. O braço editorial da empreitada, capitaneado por Seamus Deane, produziu uma gama de livros de crítica literária e cultural que galvanizaram discussões em universidades de todo o mundo anglófono. Em 1985, o simples anúncio da força-tarefa para a edição de uma antologia de escrita irlandesa foi suficiente para energizar a crítica especializada e jornalistas, que tiveram que esperar mais de seis anos para a publicação da Field Day Anthology of Irish Writing (FDA). Descrita em sua introdução como um tipo de antologia "nunca antes feita" (DEANE, 1991, p. iii,), ${ }^{1}$ tal demora para chegar às estantes foi justificada pela expansão do projeto, cujo escopo extrapolou o plano inicial de se considerarem 300 anos da história da recente da ilha para exorbitantes 1500 anos.

Quando finalmente foram publicados, os volumes I a III geraram intenso debate não apenas nos meios acadêmicos usuais (dado que praticamente todos os editores-associados e convidados eram professores universitários) mas também em periódicos de ampla circulação e projeção internacional, como o suplemento literário do tradicionalíssimo jornal The Times e a revista The Economist, ambos britânicos. Foi igualmente notável como a repercussão da publicação deu-se em todo um espectro político na República da Irlanda, sendo assunto de jornais como o liberal The Irish

\footnotetext{
${ }^{1}$ Todas as traduções dos originais em inglês são de nossa autoria.
} 
Times, o centrista Sunday Tribune e o populista Sunday Independent. Para além de uma análise do projeto editorial da $F D A$, o presente artigo busca examinar como resenhistas entre 1991 e 1993 trouxeram algumas discussões que animam o campo dos estudos editoriais para um público mais amplo. Ao abordar e criticar características específicas da edição da $F D A$, qual é a percepção da imprensa e da crítica sobre o papel dos editores? Quais conceitos e preocupações as resenhas trazem ao leitorado sobre os aspectos históricos e políticos envolvidos na edição de antologias que se querem nacionais?

Nosso foco no discurso de resenhistas justifica-se por um entendimento da recepção como parte do "modelo da vida da obra literária encarnada", como proposta por Paul Eggert (2019). De acordo com este teórico dos estudos textuais,

Sempre há, para toda obra, um continuum de produção-consumo que normalmente abrange a escrita, revisão, copidesque, edição, publicação (seja esta única ou múltipla, voltada para um público específico ou para outro), seguidas de alguma forma de distribuição, venda ou doação e, finalmente, de leitura e comentários de terceiros. [...] Os eventos textuais de escrita, revisão e produção têm resultados materiais imediatos, seja na tela, no papel ou em outra mídia. Sua leitura impulsiona a próxima etapa do processo: pelo/a escritor/a que lê e revisa em ciclos sucessivos; em seguida, por copistas, datilógrafos/as, compositores/as, agentes e revisores/as e editores/as, cada qual deve ler de modo a copiar, aumentar ou avaliar; e, por fim, na leitura feita pelo público e resenhistas (EGGERT, 2019, p. 9).

A análise das resenhas tem a vantagem adicional de incorporar o papel de resenhistas na formação de opinião junto ao público maior, leitor de ambas: antologia e resenhas. Além disso, resenhistas são figuras que também aparecem vestidas de alguma autoridade como juízes culturais e podem, como esperamos demonstrar que de fato o fizeram, influenciar posteriores decisões editoriais, ressaltando a interdependência das etapas elencadas por Eggert (2019) de forma exemplar.

Se nos distanciarmos um pouco da "obra literária encarnada" no livro, é possível ver a presença de resenhistas como parte não apenas de um "circuito de comunicação" como nos traz a história do livro (DARNTON, 2007, p. 503) mas como agentes que modulam as linhas 
de força do campo literário, como nos traz Pierre Bourdieu (1996, p. 330, ênfase nossa):

Assim, à medida que o campo se constitui como tal, a produção da obra de arte, de seu valor, mas também de seu sentido, reduzse cada vez menos exclusivamente ao trabalho de um artista que, paradoxalmente, concentra cada vez mais os olhares; ela põe em jogo todos os produtores de obras classificadas como artísticas, grandes ou pequenas, célebres, ou seja, celebradas, ou desconhecidas, os críticos, eles próprios constituídos em campo, os colecionadores, os intermediários, as conservadores, em suma, todos aqueles que têm ligação com a arte e, vivendo para a arte e da arte, opõem-se em lutas de concorrência que têm como aposta a definição do sentido e do valor da obra de arte, portanto, a delimitação do mundo da arte e dos (verdadeiros) artistas, e colaboram, por essas próprias lutas, na produção do valor da arte e do artista.

Entendemos que, além de partícipes do campo da arte de forma mais ampla, resenhistas fazem parte da crítica e, como indicado por Bourdieu no trecho da ênfase, também constituem o campo à medida que possuem certo grau de autonomia e regras próprias. Existiria nesse campo da crítica concorrência homóloga entre os diferentes tipos de resenhistas, o que justifica nossa distinção entre resenhas publicadas em periódicos acadêmicos daquelas veiculadas na imprensa, ainda que em alguns casos, bastante especializada, como é o caso da London Review of Books, por exemplo.

Por fim, retornando à questão da circularidade que pode ser vislumbrada no modelo de Eggert (2019) e no circuito de Darnton (2007), buscamos no "novo modelo para o estudo do livro" proposto por Thomas R. Adams e Nicolas Baker (2001), em seu estudo sobre O livro na sociedade, uma forma de se sistematizar "toda a conjuntura socioeconômica" (ADAMS; BAKER, 2001, p. 14) que influencia direta e indiretamente o ciclo de vida do livro. Nesse mapa, o livro - na verdade o "documento bibliográfico" (ADAMS; BAKER, 2001, p. 13) - ocupa o centro, e nas periferias são representadas as pressões feitas por forças indiretas em quatro zonas distintas: influências intelectuais; influências políticas, legais e religiosas; as pressões comerciais; e o comportamento social e gosto. Fecha-se ao redor do centro um circuito com os cinco 
"eventos" da vida do livro: publicação, manufatura, distribuição, recepção e sobrevivência, "cuja sequência constitui um sistema de comunicação e que pode, por sua vez, precipitar novos ciclos" (ADAMS; BAKER, 2001, p. 15). Em relação ao evento da recepção, os teóricos declaram:

No entanto, por mais difícil que seja, entender a recepção é muito importante se quisermos avaliar o impacto do livro. [...] A documentação direta consiste em dois tipos, respostas publicadas e respostas privadas. As respostas públicas consistem principalmente de resenhas e respostas ou comentários publicados. (ADAMS; BAKER, 2001, p. 27)

Para o estudo aqui apresentado, consideramos como o evento da publicação dos volumes I a III da $F D A$ alimenta o evento de sua recepção, considerada a partir da análise de resenhas publicadas em periódicos de grande circulação e como as críticas feitas por esses resenhistas, revelando alto grau de sofisticação sobre o papel da edição na antologia, teria, por sua vez, precipitado um novo ciclo de publicação, dessa vez em novo projeto editorial dos volumes IV e V (BOURKE et al, 1992). Para isso, combinamos resultados de buscas em bases acadêmicas do Portal Capes, no Google e nos arquivos digitais dos jornais e revistas, assim como por cruzamento de referências feitas em resenhas já recuperadas, visando uma maior abrangência. Posteriormente, as resenhas capturadas foram selecionadas pelos coautores em função de sua relevância e abordagem de temas centrais aos estudos editoriais. Compõem o corpus de análise deste artigo, enfim, sete resenhas no período de 1991 a 1993: de Colm Tóibín, para o jornal dublinense The Sunday Independent em 24/11/1991; de Richard Kearney, para o também dublinense The Sunday Tribune, de 01/12/1991; de Eileen Battersby para o The Irish Times, de 04/01/1992; de Siobhán Kilfeather para a revista literária The London Review of Books, de 09/01/1992; de Edna Longley para a mesma revista e na mesma data; de Roy Foster, para o suplemento literário do britânico The Times Literary Supplement, de 27/03/1992; e de Ben Howard, para a revista acadêmica americana Sewanee Review, em seu número de janeiro a março de 1993.

\section{A companhia Field Day: da performance à edição}

No ano de 1980, o ator Stephen Rea e o dramaturgo Brian Friel, ambos da Irlanda do Norte, uniram-se para montar uma peça de Friel, 
Translations, na cidade de Derry ${ }^{2}$ - palco do infame Domingo Sangrento oito anos antes. Importante nodo dos conflitos entre unionismo e nacionalismo, associados, respectivamente, às comunidades protestante e católica, Derry, mais que a capital Belfast, ocupa um lugar de destaque no período da história do Arquipélago Norte, que inclui as ilhas britânicas e irlandesas. Conhecido, eufemisticamente, como os Troubles, o conflito durou décadas e envolveu grupos paramilitares como o Exército Republicano Irlandês (IRA), a Associação de Defesa de Ulster (UDA), o Reino Unido e a República da Irlanda. Meses depois da estreia da peça, Rea e Friel fundariam a Field Day Theatre Company, que viria a se estabelecer, ao longo da década de 1980, como agente de destaque no cenário cultural irlandês, buscando explorar por meio do teatro as tensões históricas, sociais e culturais na ilha, especialmente as questões nacional e identitária. O projeto inicial da companhia expandiu suas atividades para além do teatro com a instituição de um painel de diretores composto por figuras importantes do circuito intelectual das duas Irlandas, como o poeta e professor Tom Paulin, o músico e documentarista David Hammond, o também poeta Seamus Heaney, o crítico cultural Seamus Deane e, por fim, o dramaturgo Thomas Kilroy. Nos arquivos dos diretores é possível identificar que já estava praticamente estabelecida em 1982 "a abordagem tripla da companhia para a redefinição cultural da Irlanda" (DEANE, 2009 , p. 9) e que incluía o teatro (com novas peças e performances em turnês pelas províncias), os panfletos teórico-políticos e o projeto de antologia que levaria à $F D A$.

Em termos de publicações, os chamados panfletos foram rápida e periodicamente publicados em séries que buscavam investigar as ligações entre política, cultura e literatura irlandesas. Em um destes panfletos, Ireland's Field Day (1985), Seamus Deane escreve que a companhia "pode e deve contribuir para a solução da atual crise produzindo uma análise das opiniões, mitos e estereótipos estabelecidos que se tornaram tanto um sintoma como uma causa da atual situação" (DEANE, 1991, p. vii). Em sua crítica cultural, os panfletos da Field Day enxergam a crise política na Irlanda do Norte como recrudescimento de desequilíbrios originados pelo colonialismo, assumindo assim uma perspectiva pós-

\footnotetext{
${ }^{2}$ Embora a cidade seja conhecida como Londonderry pelo governo britânico e apoiadores unionistas, optamos pela grafia Derry porque é como os diretores da Field Day referem-se ao local.
} 
colonial - evidente principalmente em publicações como Nationalism, Colonialism and Literature (EAGLETON, 1990), com a participação de Edward Said, entre outros. É no contexto desse projeto de confrontar mitos e estereótipos que se deu a empreitada de elaborar uma antologia de escrita irlandesa que possibilitasse um retrato mais abrangente do desenvolvimento histórico e cultural da ilha. Contudo, devido à vastidão do projeto, vários anos foram necessários para que os dois núcleos da FDA fossem publicados.

A Field Day Anthology of Irish Writing, com tiragem inicial de 1500 cópias e distribuição pela editora Norton nos EUA e Faber no Reino Unido, foi finalmente publicada em outubro de $1991 \mathrm{em}$ três volumes, totalizando mais de 4000 páginas, ao elevado preço de capa de US\$ 150 ou $£ 150$ (PELLETIER, 2013). A materialidade dos tomos reflete a ambição do projeto, trazendo textos produzidos na ilha ou a ela relacionados, não apenas em língua inglesa e irlandesa, mas também em latim e normando. A principal novidade da antologia é precisamente sua colossal escala e ambição, como demonstra o próprio título: "Irish writing" em vez de "Irish literature". Diferentemente de antologias anteriores que selecionam apenas ou principalmente gêneros tradicionalmente literários, a inclusão de mais formas de escrita, como discursos políticos, diários e pronunciamentos públicos, mais que mera inovação mercadológica, busca dar corpo a um contexto mais amplo da cultura e pensamento sobre as Irlandas ao longo dos séculos.

Quanto ao aspecto material dos volumes, os três livros padronizados e encadernados em azul-escuro, com letras e decoração evocando nós celtas em baixo-relevo dourado, são acondicionados em estojo de $24 \mathrm{~cm}$ de altura. O nome que aparece na lombada é o de Deane, editor-geral da antologia, enquanto Andrew Carpenter e Jonathan Williams são assinalados como editores-associados na folha de rosto. Deane (1985, p. iv) assina a introdução geral, em que descreve os objetivos do projeto, destacando-se aqui o de demonstrar "como os cânones são estabelecidos e o grau em que operam como sistemas de ratificação e autoridade".

A organização é essencialmente cronológica, embora ocorram algumas sobreposições. Certas seções são determinadas linguisticamente, como é o caso, por exemplo, de literatura em irlandês antigo, irlandês médio e literatura da Irlanda normanda, grupo que abre o primeiro volume e data de cerca de 550-1660. Outras seções são delimitadas por tema ou por gêneros textuais - exemplos podendo ser encontrados no 
grupo seguinte, descrito tematicamente apenas como "Uma mudança de perspectiva (1690-1830)" e na seção 9 do volume I, "Teatro (1690-1800)", respectivamente. As seções ficam a cargo de 21 editores-convidados, a maioria deles doutores e professores em departamentos universitários de literatura e história e, como já dito, todos eles homens.

O início de cada seção conta com uma introdução do contexto histórico maior e cada texto ou excerto é precedido de curtas notas introdutórias entre colchetes, em sua maioria com alguma descrição bibliográfica do texto em questão. Ao final de cada seção há referências bibliográficas completas e notas biográficas de autores/as. Todo o texto é diagramado em duas colunas, disposição especialmente adequada para as seções de poesia e para os textos apresentados em formato bilíngue. As notas são de rodapé, dentro da prática de editora Norton para suas edições críticas e antologias. Outros aspectos descritivos serão abordados neste artigo à medida que mencionados por resenhistas.

\section{A publicação como "um grande evento para os estudos irlandeses"}

A maioria das resenhas dos três primeiros volumes reconhece a importância da antologia para os estudos irlandeses, devido principalmente à sua abrangência e quantidade de textos disponibilizados. Chama atenção, no entanto, como as resenhas selecionadas diferem do que David Greetham (2013, p. 17) caracteriza como padrão nos veículos em que as encontramos:

Resenhas típicas de edições importantes em publicações como The New York Review of Books ou The New York Times Book Review (e até mesmo The Times Literary Supplement) terão pouco ou nada a dizer sobre a edição real, preferindo concentrar-se nos detalhes mais suculentos da biografia do autor em vez de como (e com que confiabilidade) o texto foi estabelecido.

Nesse sentido, as resenhas que marcam o evento da recepção da $F D A$ nos anos 1990 vão muito além da noção do trabalho editorial como um "serviço" prestado a críticos e leitores, o que nos motivou a apresentá-las aqui como estudo de caso da recepção de um projeto editorial ambicioso. 
Mesmo resenhistas que tecem fortes críticas negativas a outros aspectos da edição, conforme abordaremos mais à frente, reconhecem a $F D A$ como uma "edição importante" e o fazem justamente no tipo de publicação a que se refere Greetham. Tanto o romancista Colm Toíbín (1991) quanto Siobhán Kilfeather (1992) ressaltam a abrangência do projeto editorial e marcam a chegada às estantes como um evento: "Estes três volumes [...] trazem à cultura impressa uma espantosa gama e variedade de escritos de diversas línguas, períodos e gêneros e sua publicação é um grande evento para os estudos irlandeses" (KILFEATHER, 1992). Ao estabelecer a ponte entre as diferentes línguas representadas na antologia e a recuperação de textos de um passado distante, a resenhista demonstra compreender a conexão entre a edição de antologias nacionais e projetos de nação. Ressaltamos a percepção da resenhista porque essa conexão marca um momento-chave no advento dos estudos bibliográficos na Europa do século XIX, com os estudos pioneiros de Karl Lachmann:

sob a influência de ideias românticas do passado nacional, especialmente em uma Alemanha politicamente dividida que precisava urgentemente de um passado nacional unificado, textos medievais no vernáculo foram redescobertos, colecionados, editados e apresentados como prova de uma continuidade histórica do Volk, do grupo étnico, da nação. (LERNOUT, 2013, p. 65)

Em seu histórico do desenvolvimento do que chama de "teoria editorial continental", Geert Lernout (2013) ressalta também que "quase toda cultura nacional na Europa, incluindo culturas regionais como a catalã ou flamenca, buscaram legitimar-se como nação publicando textos de seu passado literário" (LERNOUT, 2013, p. 74) e é possível identificar uma analogia na Irlanda dividida dos séculos XX e XXI, com o mesmo impulso de legitimação. As novas traduções para o inglês moderno, encomendadas especificamente para o projeto e apresentadas lado a lado com os textos de partida, somam-se à "restauração"3 de obras dificilmente disponíveis por serem edições esgotadas, esquecidas, ou

\footnotetext{
3 "Restauração" aparece como termo preferido para descrever a função do editor por R. W. Chapman, editor da Clarendon Press que estabeleceu as políticas editoriais, no período entreguerras, da nova série Oxford English Texts (SUTHERLAND, 2013, p. 43). Chapman é figura importante da tradição britânica, ainda que não tenha tido a mesma influência dos
} 
que jamais alcançaram grande circulação. Esses esforços são aspectos comentados em diversas resenhas.

Se as traduções chamam atenção dos/as resenhistas, outras colaborações da $F D A$ também são discutidas, o que deixa claro que percebem o aspecto social do texto e o papel de editores como seus mediadores. As notas de rodapé são vistas como essenciais à experiência da antologia e são entendidas como responsabilidade importante dos editores - quando são bem-feitas e quando não o são, embora a ênfase geralmente caia no segundo caso, como indica um artigo recente sobre a prática e fenomenologia das notas: "de certa forma, escrever notas é como traduzir: é mais fácil apontar o que está errado do que certo. Além de erros fatuais, resenhistas geralmente acham as notas excessivas, muito interpretativas ou, pior, desnecessárias" (VAN MIERLO, 2020, p. 20). Roy Foster (1992) percebe inconsistências no nível das notas: "A contribuição editorial aqui é heroica, frequentemente esplêndida, mas desigual. A glosa das palavras é inconsistente; 'Colleen' [termo comum para 'moça'] merece explicação, mas 'the Ribbon snake' [?], não" (FOSTER, 1992, p. 6). Kilfeather (1992) também critica o critério para as notas, especialmente nas seções posteriores da antologia:

Não há um padrão para as notas. [...] Em algumas das seções
iniciais, as notas são excelentes; em muitas das seções posteriores,
no entanto, transparece uma confusão sobre quem é o público
esperado e a escolha do que glosar segue uma arbitrariedade
quase inane.

Kilfeather (1992) revela sua expectativa que editores devem atentar para a projeção de um público-leitor. Encabeçada na tradição anglófona por D. F. McKenzie, a virada social dos estudos editoriais, textuais e bibliográficos propõe que uma "visão panóptica" da disciplina deveria considerar os mais diversos agentes que o objeto-livro documenta. Para o teórico, nenhum partícipe das interações humanas e institucionais é alheio à bibliografia e leitores/as não apenas alguém para quem o livro deve significar alguma coisa mas também agentes capazes de "regenerar criativamente" os livros que leem (McKENZIE, 1999, p. 12). O foco no público-leitor é o argumento central de Paul Eggert (2019, p. 176) para

\footnotetext{
"Novos Bibliógrafos" A. W. Pollard, R. B. McKerrow, and W. W. Greg, cujas metáforas tendiam a modelos mais biológicos de "descendência" (GREG, 1966, p. 259).
} 
quem, "embora editores/as acadêmicos/as concentrem-se intensamente nos textos documentais de uma obra, toda edição é preparada para leitores. Edições acadêmicas cumprem seu destino no ato da leitura e buscam alcançar o futuro que antecipam". Parte da leitura que revitaliza a "obra viva" é a inscrição de marginália e anotações de todo tipo (EGGERT, 2019, p. 114). Foster (1992) e Kilfeather (1992) também atentam para esse aspecto em suas resenhas e criticam a escolha de papel fino demais para permitir que se façam anotações legíveis (FOSTER, 1992, p. 5).

\section{Anátema ou beatificação: a ideologia do projeto editorial e processos de canonização}

Uma das principais críticas aos três primeiros volumes é o viés ideológico que governa as seleções feitas na antologia. A declaração dos editores que "o objetivo da antologia não seria construir um cânone, mas demonstrar um exemplo de como eles são estabelecidos" (DEANE, 1991, p. xix) não é aceita de forma acrítica pela maioria dos/as resenhistas. Foster (1992, p. 5), por exemplo, demonstra um ceticismo salutar quanto a essa declaração contestável e afirma que, independentemente da renegação, o processo de canonização sempre decorre desse tipo de antologia. Grande parte das resenhas faz menção a algum conceito mais ou menos definido de ideologia em referência aos critérios seleção de autores/as; outras, em relação a quais textos desses/as autores/as são selecionados. Por fim, uma minoria considera o paratexto editorial, entendido aqui como as próprias seções que organizam os volumes, os ensaios que abrem cada seção, as notas introdutórias que precedem cada texto ou excerto, as notas explicativas de rodapé e as notas biográficas ao fim de cada seção.

Embora reconheça que os critérios para inclusão na antologia sejam amplos e abranjam também quem escreve na Irlanda e mesmo quem escreve sobre a Irlanda, ainda que britânico/a ou estadunidense, Foster (1992) também nota uma ligação entre esse critério e a posição política dos editores da antologia e decreta que "inclusão depende se o texto em questão preenche o projeto editorial" (FOSTER, 1992, p. 6). Citando os objetivos anunciados na introdução geral, ele questiona: "Talvez o que Spenser e Cromwell escrevem sobre a Irlanda encaixe-se melhor com a visão dos antologistas do que seriam atitudes coloniais 
'altamente reconhecíveis', enquanto que as visões de Thackeray, Trollope e Gladstone não o são?” (FOSTER, 1992, p. 6). Um argumento similar é encontrado na resenha de Toíbín (1991), que afirma que a presença de Spenser e Cromwell ocorre "porque o editor preocupa-se em mostrar que que a escrita irlandesa conta a história não da Irlanda, mas da relação da Irlanda com a Inglaterra" (TOÍBÍN, 1991, p. 8). As resenhas que debatem esse aspecto ideológico da edição revelam uma sofisticação no entendimento do papel da política, entendida de forma mais ampla, nos processos de textualização e da impossibilidade de uma suposta neutralidade. Teóricos dos estudos editoriais e textuais também alertam sobre os perigos de uma crença na imparcialidade entre editores, julgando que

talvez por uma devoção à sapiência, algum editor possa querer acreditar que uma nova edição, em livro ou formato eletrônico, possa vir à luz com o doce beijo da erudição neutra. Tal visão tende a ser ingênua na melhor das hipóteses e fraudulenta na pior (SHILLINGSBURG, 2006, p. 17).

Não se trata, no caso da $F D A$, de um viés sub-reptício: tais decisões são coerentes com o objetivo declarado por Deane (1991, p. iv) na introdução geral de reconhecer "o poder da tradição canônica inglesa de absorver uma grande quantidade de escritos que, de um ponto de vista diferente, podem ser reclamados pela tradição irlandesa". Requerer como irlandeses autores que fazem parte de cânones da língua inglesa alinha-se bem com a ideologia da Field Day: basta lembrar que Seamus Heaney, ganhador do Nobel de literatura de 1995 e o mais conhecido diretor da companhia escreveu em 1993 uma carta-poema protestando contra sua inclusão como poeta britânico na antologia The Penguin book of contemporary British poetry. ${ }^{4}$ Edna Longley (1992) identifica nessa postura importante ponto-cego: “'A tradição irlandesa', quando concebida monoliticamente, nem sempre foi aberta, por exemplo, a Swift, Burke e Goldsmith", autores nascidos na Irlanda mas ideológica e politicamente mais alinhados aos interesses anglo-irlandeses, à igreja anglicana e ao conservadorismo no Parlamento Britânico.

\footnotetext{
${ }^{4}$ Para discussão de An open letter, ver a mais recente biografia do escritor On Seamus Heaney (FOSTER, 2020, p. 84-87).
} 
Outros resenhistas também perguntam o que tornaria alguém suficientemente irlandês para ser incluído na antologia. Foster (1992) remonta ao século XIX, relatando, inclusive, que discussão similar foi instigada por ninguém menos que W. B. Yeats, o primeiro poeta irlandês ganhador do Nobel. Os nomes citados por Yeats nas páginas de jornais a partir da segunda metade da década de 1880 ecoam na introdução geral da $F D A$ e são, em grande parte, os mesmos mencionados por Longley (1992), acima. Dentre Jonathan Swift, George Berkeley, Laurence Sterne e Oliver Goldsmith, todos passam pelo crivo dos editores exceto Goldsmith, que é "cortado por ser considerado insuficiente ou inadequadamente irlandês" (FOSTER, 1992, p. 6). O resenhista ressalta que não é apenas a introdução geral que explicita os critérios de inclusão: os vieses de seleção se fazem notar em todo o paratex to editorial. Estabelecendo uma analogia certeira com os processos da Igreja Católica, que no início dos anos 1990 ainda era umas das instituições mais influentes na República da Irlanda, Foster (1992, p. 6) considera que ficam "à espreita nas notas biográficas" as decisões sobre a quem cabe anátema ou beatificação e, assim, eventual canonização, aqui entendida tanto no sentido religioso quanto literário.

Muitos/as resenhistas criticam o que percebem como um foco exagerado nas relações coloniais entre Irlanda e Reino Unido (em suas diversas configurações históricas) em detrimento de outros aspectos e seu marcado posicionamento nacionalista/republicano. Antecipando-se a essas críticas, Richard Kearney (1991, p. 2), em texto para o centrista Sunday Tribune, ratifica o objetivo declarado da antologia de acolher a pluralidade de narrativas e tradições na ilha, afirmando que a obra "não é um exercício de nostalgia nacionalista. Pelo contrário, é um lembrete da falta de qualquer consenso significativo nesta ilha". Trata-se de um caso isolado, no entanto, já que a percepção da ênfase nacionalista é recorrente em outras resenhas. Battersby (1992, p. 5) relembra que "desde a sua criação em 1980, a Field Day nunca tentou disfarçar uma agenda cultural decididamente nacionalista". A autora também considera que muitas das objeções contra a antologia não seriam devidas a suas inclusões e omissões, mas pelo seu posicionamento nacionalista. Embora Battersby (1992, p. 5) critique os editores, ela ressalta que Deane "se propôs a reconhecer e enfrentar o passado, não a escondê-lo" e que "não se pode negar que grande parte da literatura irlandesa é produto da experiência colonial e que o imperialismo teve seu papel ao influenciar a escrita na Irlanda". 
Contudo, "grande parte" certamente não é toda a literatura e resenhistas como Toíbín lamentam as formas como a orientação ideológica dos editores determina sobremaneira não só a seleção de quais textos são incluídos mas também como eles devem ser lidos. $\mathrm{O}$ exemplo escolhido por Tóibín (1991) é certeiro: a James Joyce, o mais reconhecido ficcionista da Irlanda moderna, é dedicada toda uma seção. No entanto, o ensaio introdutório escrito por Deane (1991) contextualiza Joyce em termos coloniais/pós-coloniais e não por suas características modernas ou pós-modernas, igualmente ou mais importantes para sua obra, de acordo com Tóibín (1991) - e provavelmente grande parte da crítica internacional.

Algo comum a várias das resenhas são as críticas não apenas à seção de Joyce mas às seções de ficção como um todo, especialmente no século XX. Longley (1992) também questiona a ênfase da seleção temática, escrevendo que

as escolhas da escrita do final do século XX, uma matriz para o futuro, muitas vezes dependem de conteúdos previsivelmente irlandeses. Não há sequer sombra de julgamentos de valor ousados ou surpresas estéticas. (LONGLEY, 1992, s.p.)

Tal viés não se limitaria à ficção: Longley (1992) também identifica que na seção de poesia contemporânea (1950-90), a cargo de Declan Kiberd, o editor parece ter encontrado "problemas editoriais"; para ela, quando Kiberd afirma que os poetas contemporâneos, quanto à política no norte e no sul, têm "notavelmente pouco a dizer", isso é um sinal de que o que tais poetas têm a dizer não corresponde ao que ele (e demais editores da antologia) esperam ouvir.

Nem todas as resenhas discutem o projeto político com o mesmo grau de sofisticação. Para o resenhista do periódico estadunidense Sewanee Review, a antologia, salvo raras exceções, "reflete uma subordinação de valores estéticos a políticos" (HOWARD, 1993, p. 137). Após examinar a inclusão de certas obras em detrimento de outras, declara:

Quando Deane inclui os poemas de Lionel Johnson "NinetyEight" e "Parnell" logo depois de admitir que "os poemas de Johnson sobre assuntos irlandeses estão muito longe de serem seus melhores", percebe-se claramente o propósito e a linha do projeto da Field Day (HOWARD, 1993, p. 137). 
Ao repisar na dicotomia de estética x política, ele parece sugerir que existem escolhas editoriais apolíticas, diferentemente do que nos apontam teóricos debruçados sobre esta questão:

\begin{abstract}
Em termos de seleção textual, a política condiciona os próprios materiais que atraem a atenção de um dado editor e da instituição onde trabalha. As preferências por fontes textuais específicas também podem se dividir em linhas nacionais e de classe (com materiais considerados de elite recebendo maior atenção em um contexto, enquanto aqueles de origens mais modestas são priorizados em outro). Em termos de disseminação, as formas materiais das edições codificam relações de poder e aspirações políticas em diferentes graus de explicitação (WARREN, 2013, p. 124).
\end{abstract}

A admissão de Deane sobre o critério de seleção dos poemas de Johnson para a $F D A$ configura um caso de alto grau de explicitação do projeto político da edição por parte dos editores.

\title{
"As loucas do anexo": a baixa representação das mulheres nos volumes I a III como decorrentes do projeto de edição
}

Se Warren (2013), na formulação acima, destaca as linhas nacionais e de classe como divisores das atenções de editores/as, outra também criou a exclusão de todo um grupo de textos: a de gênero social. A mais ferrenha reação contra a $F D A$ viria da crítica feminista. Além da ausência de mulheres no projeto, a antologia que declarava buscar acomodar uma pluralidade de narrativas na verdade trazia muito pouco da escrita das mulheres, ao mesmo passo que ignorava completamente o desenvolvimento e relevância do feminismo na ilha. Toíbín (1991) questiona a ausência, entre outros, de discursos de Mary Robinson, a primeira presidenta da Irlanda e de documentos relacionados ao movimento feminista; Battersby (1992) estranha que uma antologia que se debruça tão profundamente sobre o pensamento político ao longo da história irlandesa não inclua trechos de importantes julgamentos "que determinaram a vida constitucional da Irlanda, especialmente das mulheres", ignorando também as contribuições sociais e políticas destas.

Kilfeather (1992) afirma ter contado 39 autoras na antologia, o que caracteriza como "de forma alguma uma presença desprezível"; para 
ela, o problema maior está na quase completa ausência - exceto por um ensaio de Sheehy-Skeffington intitulado "War and Feminism" - dos debates e polêmicas sobre os direitos das mulheres e sexualidade. "De fato", ironiza, "é possível ler esta antologia de capa a capa sem jamais se perceber que a sexualidade é uma questão política controversa na história irlandesa". Um de seus comentários demonstra como as questões de gênero e sexualidade são atenuadas em favor do foco dominante da antologia, o problema nacional/colonial:

Os principais escândalos sexuais do final do século XIX e início do século XX, envolvendo [Charles Stuart] Parnell, [Oscar] Wilde e [Roger] Casement são todos tratados como se ganhassem significado principalmente em um contexto de repressão e distorção britânicas (KILFEATHER, 1992).

As identidades sobre as quais a antologia verdadeiramente se debruça são as nacionais. Longley (1992) conecta o que poderiam parecer duas facetas distintas - o posicionamento nacionalista (com uma inflexão norte-irlandesa) da antologia e a ausência de documentos sobre o feminismo na Irlanda - apontando uma como possível motivo da outra:

As pautas das mulheres vexam os nacionalistas do norte porque destacam as controvérsias entre Igreja e Estado na República (acerca do divórcio e liberdades ginecológicas) e, assim, expõem a dimensão religiosa do conflito da Irlanda do Norte (LONGLEY, 1992).

Foster (1992) examina, por sua vez, outras possíveis razões das exclusões de literatura de autoria feminina. Percebendo a inclusão de Elizabeth Bowen apenas por seus contos com temáticas mais marcadamente irlandesas, o limitado espaço dedicado a Somerville e Ross e a total ausência de Molly Keane, ele especula que essas mulheres são excluídas porque complicam o "enredo da antologia", "não apenas porque são do gênero errado, mas porque falam com o sotaque errado" (FOSTER, 1992, p. 6). O sotaque, neste caso, faz referência tanto à divisão de classe quanto à denominação religiosa, já que as autoras, pertencentes à Ascendência Anglo-Irlandesa, são de origem protestante. Kilfeather (1992) também nota a ausência de escritoras norte-irlandesas como Charlotte Elizabeth, Amanda McKittrick Ros, Frances Browne e 
Anne Crone, "cujas linhagens de unionismo e feminismo perturbariam de forma instigante a metanarrativa" (KILFEATHER, 1992) dos editores.

Considera-se que a intensa reação contra o papel marginal das mulheres na antologia levou a Field Day, através de Deane, a declarar em 1992 o intuito de produzir não uma nova edição dos volumes I a III que incorporasse mais escritoras, mas volumes adicionais (PELLETIER, 2013). Dedicada à escrita das mulheres e editada por um time composto apenas por acadêmicas, escritoras e jornalistas e publicada conjuntamente como volumes IV e V em 2002, essa segunda fase da FDA, com cerca de 3000 páginas, gerou um novo evento editorial de alto impacto. No entanto, em livro de 1994, Longley já prevê a possibilidade de um descompasso entre os volumes de 1991 e 2002: ao tomar conhecimento do projeto para edição dos novos volumes, a crítica observa que tal configuração pouco faria para redimir os diretores da Field Day da marginalização das mulheres, já que essas continuariam, para eles, como "as loucas do anexo", em uma alusão ao texto clássico do feminismo anglófono The Madwoman in the Attic (GILBERT; GUBAR, 1979).

\section{Considerações finais}

Em termos de padrões entre as sete resenhas selecionadas, observamos frequentes questionamentos sobre uma fixação do cânone irlandês por meio da publicação da $F D A$, algo que a maioria dos/as resenhistas entende de forma bastante crítica, notando, inclusive, certa inconsistência da declaração de Deane em sua introdução. Podemos ver que os debates sobre o papel das edições no estabelecimento, manutenção e reconfiguração de cânones fazem parte das preocupações dos/as resenhistas quando lidam com antologias. No caso das antologias nacionais, é uma questão ainda mais premente e considera-se como, no caso estadunidense:

as escolhas editoriais têm moldado de forma furtiva o cânone literário americano (sic) durante séculos, forjando legados autorais, produzindo propaganda regional e nacional e, geralmente, funcionando como um fator determinante para o que e como consideramos a literatura americana (GAILEY, 2015, p. 1). 
A visão diacrônica proposta por Gailey (2015) torna a conexão com o século XIX a que se refere Foster (1992) em sua resenha ainda mais importante para nossa reflexão sobre o papel da imprensa na formação de cânones nacionais irlandeses. Em carta ao editor do jornal The United Ireland de $1^{\circ}$ de dezembro de 1894, como parte da controvérsia apontada por Foster (1992, p. 5), Yeats (1986, p. 417) já declarava:

Não acredito, todavia, que estaremos mais próximos dessa meta [de fomentar um público leitor] ao exigir que os escritores irlandeses desenvolvam "indiferença adamantina ao julgamento de todos os públicos exceto o do público da Irlanda" como "única posição honrosa" a se assumir [como sugerira o editor]. Essa não é, de maneira alguma, uma questão que deva envolver escritores, mas sim jornalistas, editores e donos de jornais na Irlanda. Se críticas de qualidade forem escritas em jornais irlandeses, a elas se dará a devida importância, tanto por parte dos escritores quanto do público. Porém, enquanto os críticos irlandeses continuarem forçados a resenhar livros irlandeses em jornais ingleses, não haverá crítica na Irlanda a que se dar ouvidos. Um ou dois dos nossos jornais estão fazendo algo, muito pouco, mas no geral o amadorismo reina supremo e os poucos artigos que demonstram algum conhecimento e também aquela qualidade, ainda mais rara, que é o discernimento, passam despercebidos e perdem-se em meio a um ritual vazio de convenções e preconceito.

Em 1991, é possível considerar que o campo literário irlandês já tinha alcançado o nível de autonomia nacional a que aspirava Yeats (1986) e que as resenhas em jornais irlandeses (assim como já era o caso dos britânicos e estadunidenses) tiveram impacto na recepção da $F D A$, sendo inclusive parte importante de eventos que desencadearam o novo ciclo de produção dos volumes IV e V.

Nota-se na exclusão de editoras mulheres dos volumes I a III da FDA uma grande ironia histórica. O projeto de antologia nacional que mais se parece com o que os editores quiseram para a $F D A$ foi o The Cabinet of Irish Literature (1879), publicado originalmente em quatro volumes sob editoria de Charles Read, que passa, em sua nova edição expandida, para as mãos da escritora Katharine Tynan Hinkson em 1902. $\mathrm{O}$ fato de a mais extensa e recente antologia precursora ter sido editada por uma irlandesa infelizmente foi algo que parece não ter sido valorizado pelos editores, quase 90 anos depois. 
Parte importante da controvérsia na recepção da $F D A$ deu-se em torno da baixa representação das mulheres, tanto como escritoras dignas de antologização quanto pela total ausência de editoras-convidadas no projeto original. $\mathrm{O}$ contexto em que os volumes $\mathrm{IV}$ e $\mathrm{V}$ foram desenvolvidos era muito diferente daquele à época do lançamento dos primeiros volumes. No âmbito político, tinham sido alcançados avanços no processo de pacificação na Irlanda do Norte, que culminaram no Acordo da Sexta-feira Santa de 1998. Já no âmbito acadêmico, é possível perceber, ainda que com algum atraso em relação às universidades estadunidenses, a maior proeminência dos estudos feministas e de abordagens críticas que levam em conta questões de gênero. Para fazer justiça ao evento da publicação dos volumes IV e V, em outro artigo consideraremos as interseções dos estudos editorais e da sociologia da recepção para analisar como resenhistas avaliam o projeto feminista de edição ${ }^{5}$ de uma antologia nacional.

\section{Referências}

ADAMS, Thomas R.; BAKER, Nicolas. A Potencie of Life: Books in Society. London: British Library, 2001.

BATTERSBY, Eileen. Field Day and the Writing Tradition. The Irish Times, Dublin, 4 jan. 1992. The arts, p. 5.

BOURDIEU, Pierre. As regras da arte: gênese e estrutura do campo literário. São Paulo: Companhia das Letras, 1996.

BOURKE, Angela et al (ed.). The Field Day Anthology of Irish Writing, v. 4-5: Irish Women's Writing and Traditions. Cork; Nova York: Cork University Press; Field Day, 2002.

DARNTON, Robert. "What Is the History of Books?" Revisited. Modern Intellectual History, Cambridge, v. 4, n. 3, p. 495-508, 2007. DOI: http:// doi.org/10.1017/S1479244307001370

DEANE, Ciarán. Brian Friel's Translations: The Origins of a Cultural Experiment. Field Day Review, Dublin, v. 5, p. 6-47, 2009.

\footnotetext{
${ }^{5}$ Como já proposto por D.H. Reiman (1988) há várias décadas, em um dos periódicos mais conservadores da área de estudos textuais, a TEXT.
} 
DEANE, Seamus et al. (ed.). The Field Day Anthology of Irish Writing. Derry; Nova York: Field Day; Norton, 1991. v. 1-3

EAGLETON, Terry et al. Nationalism, Colonialism and Literature. Minneapolis: University of Minnesota Press, 1990.

EGGERT, Paul. The Work and the Reader in Literary Studies: Scholarly Editing and Book History. Cambridge: Cambridge University Press, 2019. DOI: http://doi.org/10.1017/9781108641012.

FIELD DAY THEATRE COMPANY. Ireland's Field Day. Londres: Hutchinson, 1985.

FOSTER, R. F. Nations, yet Again: Constructing or Deconstructing an Irish Canon?. Times Literary Supplement, Dublin, v. 10, n. 4643, p. 5-7, 27 mar. 1992.

FOSTER, R. F. On Seamus Heaney. Princeton: Princeton University Press, 2020. DOI: http://doi.org/10.1515/9780691211473.

GAILEY, Amanda. Proofs of Genius: Collected Editions from the American Revolution to the Digital Age. Ann Arbor: University of Michigan Press, 2015. DOI: http://doi.org/10.2307/j.ctv65sx4r.

GILBERT, Susan; GUBAR, Sandra. The Madwoman in the Attic: The Woman Writer and the Nineteenth-Century Literary Imagination. New Haven: Yale University Press, 1979.

GREETHAM, David. A History of Textual Scholarship. In: FRAISTAT, Neil; FLANDERS, Julia (org.). The Cambridge Companion to Textual Scholarship. Cambridge: Cambridge University Press, 2013. p. 16-41. DOI: http://doi.org/10.1017/CCO9781139044073.002.

GREG, W. W. Bibliography: An Apologia. In: GREG, W.W. Collected Papers. Edição de J. C. Maxwell. Oxford: Clarendon Press, 1966.

HOWARD, Ben. Gael and gall. Sewanee Review, Sewanee, v. 101, n. 1, p. 131-137, 1993.

KEARNEY, Richard. Puns, Ambiguities and Polyphonies. The Sunday Tribune, Dublin, 1 dez. 1991. Books, p. 2. 
KILFEATHER, Siobhan. The Whole Bustle. London Review of Books, Londres, v. 14, n. 1, 9 jan. 1992. Disponível em: https://www.lrb.co.uk/ the-paper/v14/n01/siobhan-kilfeather/the-whole-bustle. Acesso em: 29 ago. 2020.

LERNOUT, Geert. Continental Editorial Theory. In: FRAISTAT, Neil; FLANDERS, Julia (org.). The Cambridge Companion to Textual Scholarship. Cambridge: Cambridge University Press, 2013. p. 61-78. DOI: http://doi.org/10.1017/CCO9781139044073.004.

LONGLEY, Edna. Belfast Diary. London Review of Books, Londres, v. 14, n. 1, 9 jan 1992. Disponível em: https://www.lrb.co.uk/the-paper/ v14/n01/edna-longley/belfast-diary. Acesso em: 29 ago. 2020.

McKENZIE, D. F. Bibliography and the Sociology of Texts. Cambridge: Cambridge University Press, 1999. DOI: http://doi.org/10.1017/ CBO9780511483226.

PELLETIER, Martine. Un acte de définition: L'enterprise anthologique selon Field Day. In: GENET, Jacqueline et al (org.). Le livre en Irlande: L'imprimé en contexte. Caen: Presses Universitaires de Caen, 2013. p. 227-250. DOI: http://doi.org/10.4000/books.puc.935.

REIMAN, D. H. Gender and Documentary Editing: A Diachronic Perspective. TEXT: Transactions of the Society for Textual Scholarship, Ann Arbor, MI, v. 4, p. 351-359, 1988.

SHILLINGSBURG, Peter L. From Gutenberg to Google: Electronic Representations of Literary Texts. Cambridge: Cambridge University Press, 2006. DOI: http://doi.org/10.1017/CBO9780511617942.

SUTHERLAND, Kathryn. Anglo-American Editorial Theory. In: FRAISTAT, Neil; FLANDERS, Julia (org.). The Cambridge Companion to Textual Scholarship. Cambridge: Cambridge University Press, 2013. p. 42-60. DOI: http://doi.org/10.1017/CCO9781139044073.003.

TÓIBÍN, Colm. Confusion of Literary Traditions. Sunday Independent, Dublin, 24 nov. 1991, p. 8.

VAN MIERLO, Wim. Annotation and Commentary in the Modernist Edition: A critique. Modernist Cultures, Edimburgo, v. 15, n. 1, p. 69-91, 2020. DOI: http://doi.org/10.3366/mod.2020.0280. 
WARREN, Michelle R. The Politics of Textual Scholarship. In: FRAISTAT, Neil; FLANDERS, Julia (org.). The Cambridge Companion to Textual Scholarship. Cambridge: Cambridge University Press, 2013. p. 119-134. DOI: http://doi.org/10.1017/CCO9781139044073.007.

YEATS, W. B. The Collected Letters of W. B. Yeats: volume 1, 1865-1895. Edição de John Kelly e Eric Domville. Oxford: Oxford University Press, 1986.

Recebido em: 31 de agosto de 2020.

Aprovado em: 08 de março de 2021. 